\title{
PRÁTICAS DA ARTE CONTEMPORÂNEA: UMA ABORDAGEM PRAGMÁTICA A UM NOVO PARADIGMA ARTÍSTICO*
}

Argumento neste artigo que aquilo que costumamos chamar de "arte contemporânea" não é uma categoria meramente cronológica na história das artes visuais, mas um novo "paradigma" no sentido definido pelo historiador norte-americano Thomas Kuhn referente à produção científica (Kuhn, 1962). Tentarei demonstrar esta tese por meio da análise minuciosa das condições materiais, sociais, jurídicas e axiológicas sob as quais determinados objetos podem ser considerados obras de arte e menos sob aspectos estéticos. Assim, os leitores serão capazes de compreender o meu argumento, mesmo que nada conheçam sobre arte em geral e arte contemporânea em especial.

O método por mim empregado pertence ao que na França chamamos de "sociologia pragmática". Começarei com algumas observações sobre essa questão metodológica.

\section{PRAGMATISMO}

Na década de 1990, surgiu na França uma nova tendência chamada "sociologia pragmática". Esta remete tanto ao "pragmatismo" norte-americano na filosofia quanto à linguística "pragmática" (Heinich, 2009a). Salvo algumas diferenças em seus vários autores (Boltanski \& Thévenot, 2006; Hennion, 2007; Latour, 2002), esta sociologia se apoia principalmente em pesquisas empíricas fundamentadas na observação cuidadosa de ações em seu contexto atual. 
Destarte, representa não só uma "vertente crescente de teoria cultural" (Silber, 2003: 427), mas também uma renovação importante. Com sua pretensão de ser principalmente descritiva e analítica, e não crítica, ela rompe com a "sociologia da dominação" de Pierre Bourdieu (Heinich, 1998b; 2009b); e já que alega que a relatividade das ações humanas baseada em seus contextos tem se tornado uma acepção comum, que já não precisa mais ser demonstrada, mas usada apenas como ponto de partida para o trabalho analítico, ela tende a ultrapassar os "estudos culturais" anglo-americanos e o "construtivismo social” (Heinich, 2010; 2011).

No campo da sociologia das artes, essa perspectiva "pragmática" não pode ser reduzida à demonstração de Howard Becker da natureza coletiva das atividades artísticas (Becker, 1982), pois não pretende demonstrar qualquer coisa, nem dispensar a crença comum na natureza individual da experiência artística; antes, a abordagem sociológica pragmática às artes se propõe a descrever o enlaçamento íntimo entre objetos e ações humanas a fim de entender todo o conjunto de estruturas (incluindo estruturas simbólicas, como representações e valores) que compele e organiza as relações com a arte. Essa perspectiva não nos obriga a refutar a crença comum na natureza individual da arte, como o fez Becker, mas a entendê-la por meio de um esclarecimento de seus fundamentos axiológicos.

Segue um exemplo para demonstrar como a perspectiva pragmática pode ajudar a descrever e compreender o que está em jogo em situações relacionadas às artes. Quando comentam os ready-mades de Marcel Duchamp, os eruditos alegam frequentemente que o artista teria declarado: "Isto é arte"; isso, porém, não corresponde em nada aos fatos, como demonstra uma análise minuciosa daquilo que realmente aconteceu. Duchamp não disse nada: ele fez algo (comprou o mictório, pintou nele sua assinatura e a data, levou-o ao saguão onde o Salon des Indépendants recebia as obras de arte em Nova York e o instalou numa posição inversa); depois, após o mictório ser abandonado num saguão (não, porém, recusado, pois não havia júri), fez com que outros agissem. Primeiro, pediu que seu amigo Alfred Stieglitz publicasse uma fotografia da Fonte com um comentário em sua revista The Blind Man; depois aguardou. Passados quase quarenta anos, após ter se tornado uma figura artística proeminente, Duchamp decidiu produzir um pequeno número de réplicas do mictório original (que havia se perdido) e vendê-las a galerias particulares e museus públicos a partir da década de 1950. Permitiu simplesmente que os intermediários culturais fizessem o seu trabalho, que trataram e enquadraram o objeto como obra de arte, segurando, descrevendo, vendendo ou exibindo, iluminando e comentando o objeto (Camfield, 1989; Heinich, 1998a). Assim Duchamp fez com suas ações o que um sociólogo "pragmático" teria feito com palavras, ou seja, destacar a importância de intermediários no campo da arte. 
Para contar esta história deste modo, não tive que fornecer nenhum juízo de valor, nem mesmo uma interpretação: precisei apenas descrever com precisão as ações, os objetos e os contextos, baseando-me na reconstrução histórica providenciada pelos historiadores da arte. Levei em consideração também as diversas categorias de "actantes", ou atores envolvidos nas situações descritas. Por fim, tive que supor que, por trás desses atores e ações, existe algum tipo de regras do jogo ou algum tipo de frames, que fornece aos atores e ações suas "condições de felicidade", como teria dito Erving Goffman (Goffman, 1974; 1981). A abordagem pragmática permite esclarecer ou explicar precisamente essas regras ou frames, como pretendo demonstrar no caso da arte contemporânea.

A perspectiva pragmática representa uma mudança real quando comparada com as abordagens mais conhecidas da arte. Diante de uma nova proposta artística como o ready-made, o historiador da arte explicaria como essa obra conquistou seu lugar na história da arte e como seu autor pode ter sido influenciado por obras anteriores, ou como poderia vir a influenciar obras posteriores. Um economista da arte descreveria como essa obra entrou progressivamente no "primeiro mercado" de galerias; depois, no "segundo mercado" de leilões ou até mesmo de museus, e como seu preço continuou a subir. Um historiador da cultura ou um sociólogo da arte do estilo antigo explicaria como essa obra pode ser interpretada como uma testemunha visual da sociedade em que surgiu. Um filósofo ofereceria uma interpretação dessa obra para ilustrar um conceito ou determinado tipo de experiência existencial. Um sociólogo crítico denunciaria o quanto a "sociedade" demorou a reconhecer um artista inovador, ou quão injusto é "legitimar" uma pseudo-obra de arte produzida para os "dominantes" que "manipulam" a cultura a fim de colocá-la a serviço de suas "estratégias distintas". Um sociólogo pragmático, porém, não critica, não avalia, não interpreta: descreve, analisa e, por vezes, esclarece relações, estruturas ou frames invisíveis - como farei agora em relação aos frames invisíveis da arte contemporânea.

\section{ARTE CONTEMPORÂNEA E A TRANSPOSIÇÃO DE LIMITES}

"Pós-modernismo", "pós-vanguarda”, “artes plásticas" no lugar de "belas artes", "plasticiens" no lugar de "artistas" são novos nomes que emergem para designar não só novos estilos ou movimentos artísticos, mas um novo período de arte ou um novo modo de praticá-la. Indicam provavelmente uma mudança paradigmática.

Mas será que a arte contemporânea é realmente um novo paradigma artístico, no sentido da definição de Thomas Kuhn, ou seria ela meramente um período artístico? Teríamos que falar em um novo período se ela incluísse toda a produção artística da atualidade; o que não é o caso, pois encon- 
tramos hoje muitos artistas que praticam o pós-impressionismo, o pós-surrealismo ou o pós-expressionismo. A arte de hoje é composta por arte moderna (e, às vezes, até arte clássica) e arte contemporânea. Além do mais, algumas das principais figuras da arte contemporânea já morreram: Yves Klein, por exemplo, e Andy Warhol. A “arte contemporânea” não pode, portanto, ser reduzida à arte de artistas vivos, já que que ela inclui artistas já falecidos e não inclui grande parte da produção artística atual. "Arte contemporânea" é uma categoria estética de arte, um tipo de "gênero" artístico, mas num sentido mais amplo do que aquilo que se costuma chamar de "gênero": como categoria artística, a arte contemporânea se encontra no mesmo nível da arte clássica ou moderna, sendo que cada uma possui suas características próprias.

Em meu livro Le triple jeu de l'art contemporain (Heinich,1998a), sugeri algumas definições baseadas numa análise dos critérios usados para avaliar esses três modos de praticar e conceber arte. Permitam-me recordá-las rapidamente: a arte clássica exige que o artista execute o modelo padrão de figuração, seja de forma idealizada ou realística. A arte moderna exige que o artista expresse sua interioridade, o que, muitas vezes, significa a necessidade de ultrapassar os padrões da figuração clássica ou até mesmo a própria figuração, como acontece no caso da arte abstrata. A arte contemporânea exige que o artista ultrapasse os limites do senso comum, não da figuração clássica, como no caso da arte moderna, mas da própria noção de arte, inclusive a exigência moderna de um vínculo entre a obra e a interioridade do artista.

Sendo principalmente um jogo com limites, a arte contemporânea rompe tanto com a arte clássica quanto com a moderna. Uma "instalação", ou "performance", não se enquadra mais na concepção clássica ou moderna de uma obra de arte, ou seja, de uma pintura enquadrada ou de uma escultura num pedestal. Não demonstra mais nenhum vínculo entre a obra de arte e a interioridade, ou até mesmo o corpo do artista; e a ironia e a jocosidade são mais importantes do que a seriedade. Mediações técnicas ou sociais se tornam necessárias, juntamente com técnicas especiais como fotografia ou vídeo para garantir a durabilidade da obra. Além do mais, essas técnicas fogem, muitas vezes, às regras dos museus, a rotinas econômicas, a restrições de transporte e de seguro ou a técnicas de restauração. Em virtude de tudo isso, a arte contemporânea é mais do que um novo período artístico e mais do que uma nova categoria estética. Trata-se de um novo paradigma, que transforma completamente o mundo da arte. Equivale a um novo paradigma na história das ciências, como pretendo demonstrar por meio de algumas observações. 


\section{O NOVO STATUS DA OBRA DE ARTE}

Na arte contemporânea, a transgressão mais importante dos critérios comuns usados para definir a arte é que a obra de arte já não consiste exclusivamente no objeto proposto pelo artista, mas em todo o conjunto de operações, ações, interpretações etc. provocadas por sua proposição. Isto é, de fato, uma questão sociológica, questão esta que precisa ser considerada por aquele que se aventura no mundo da arte contemporânea. É a razão pela qual tantos permanecem do lado de fora, pois, às vezes, nem compreendem o que precisa ser compreendido: eles não conhecem as regras do jogo. Daí surge um conflito de paradigmas.

Retorno ao exemplo mais famoso: a Fonte de Marcel Duchamp (o próprio fato de essa obra ter se tornado um emblema da arte contemporânea, apesar de datar da Primeira Guerra Mundial, ou seja, de um período em que a arte moderna havia se tornado o novo paradigma, já comprova, por si só, que a "arte contemporânea" não representa um período na história da arte, mas uma categoria estética). Na Fonte, a obra de arte não reside na materialidade do objeto proposto (aqui, um mictório), mas no ato de propô-lo para uma exposição no Salon des Indépendants; nas muitas histórias que narram como chegou a não ser exposto e como, por fim, ressurgiu quatro décadas mais tarde na forma de réplicas vendidas a algumas galerias e museus; nos muitos protestos e até atos de vandalismo que provocou; nos comentários infindáveis que continuam a construir seu mito etc. Ou seja, a obra de arte abandonou o objeto produzido pelo artista para investir em contextos, palavras, ações, coisas, números... Daí a importância do contexto na arte contemporânea: é impossível contar a história da Fonte sem mencionar e explicar o contexto do Salon des Indépendants, a ausência de jurados, a presença de Duchamp entre os organizadores etc. etc.

Um exemplo mais recente é do artista francês Daniel Buren. Ele expõe suas listras aplicadas sobre peças de metal, colunas, paredes etc., mas sua obra de arte não reside naquele material listrado, como a maioria das pessoas suporia num primeiro momento por perceber a proposta conforme os paradigmas clássico e moderno. A obra de arte consiste na forma como todo o ambiente é reconstruído e reorganizado por meio daquilo que Buren chama de "outil visual" ("ferramentas visuais"). A arte é encontrada, portanto, no contexto em que o objeto proposto (as listras) é inserido, e não no objeto em si. Enquanto o espectador não entender essa nova regra do jogo, não poderá apreciar ou até mesmo ver o que está em jogo. As experiências da psicologia da Gestalt com a percepção visual tratam exatamente disto: ou se vê um coelho, ou se vê um pato; ou se veem as listras, ou se vê o ambiente. Passar de um para o outro depende apenas do tipo de paradigma que você aplica a tudo o que lhe é apresentado como obra de arte. 
Isso explica alguns dos protestos violentos contra esse tipo de proposta, ainda mais quando é financiado pelo poder público, comissionado e avaliado em nome do bem comum (Heinich, 1998b). Aqueles que contemplam esse tipo de obras de arte conforme o paradigma clássico ou, como acontece mais frequentemente, moderno, não conseguem entender como essas obras podem receber alguma forma de reconhecimento; inversamente, aqueles que as percebem conforme o paradigma sob o qual foram criadas não conseguem entender como algumas pessoas podem não perceber e aceitar tais razões.

\section{A DIVERSIFICAÇÃO DOS MATERIAIS}

A transgressão dos limites da arte significa também o emprego de novos tipos de materiais ou modos de apresentação. Instalações, performances, land art, arte corporal, vídeo, fotografias em cores em grande escala, multimídia e arte cibernética fazem parte do vocabulário básico do artista contemporâneo. Esta é outra grande diferença em relação à arte clássica e moderna, pois durante séculos, até o início da década de 1960, as artes visuais eram produzidas com um pequeno número de materiais bem definidos: óleo, pastel, aquarela, lápis, carvão, água-forte; papel, tela, gesso, madeira ou pedra, argila, madeira, bronze... Agora, tudo mudou. Mesmo sem ver a obra, você consegue adivinhar que se trata de arte contemporânea apenas lendo sua descrição, como: "latão", "feltro e graxa", "telas de TV”, “corais e pão”, "módulos acústicos", ou, em termos mais amplos, "materiais variados" ou "dimensões variáveis". Consequentemente, a arte do restaurador também sofreu mudanças drásticas: a arte contemporânea suscita questões de restauração completamente novas, como atestam associações profissionais específicas e revistas especializadas.

Evidentemente, existem também pinturas e esculturas na arte contemporânea. Mas são relativamente raras e normalmente são expostas sem moldura, no caso das pinturas, e sem pedestal, no caso das esculturas. Uma escultura da arte contemporânea se parece mais com uma instalação, que apresenta uma relação específica com o espaço; e uma pintura da arte contemporânea apresenta dimensões enormes, de forma que dificilmente pode ser emoldurada (o que, por sua vez, representa uma transgressão da exigência moderna conforme a qual a obra deve expressar a interioridade do artista), ou é feita de modo a se encaixar no espaço em que é exibida, exigindo assim uma continuidade entre tela e ambiente (o que, por sua vez, representa uma transgressão da definição clássica e moderna de uma obra de arte como objeto produzido por um artista). 


\section{O DISCURSO SOBRE A OBRA É PARTE DA OBRA}

A extensão da obra de arte para além da materialidade do objeto produzido ou apresentado pelo artista inclui também o discurso sobre a obra. Uma obra de arte contemporânea quase nunca existe sem um texto, assinado ou não, escrito pelo próprio artista ou, melhor ainda, por um especialista - por um crítico ou curador.

Exatamente da mesma forma como o contexto se tornou parte da obra, o discurso sobre a obra se tornou parte da proposta artística. É por isto que hoje as escolas de arte - pelo menos na França - incluem em sua agenda pedagógica também a mestria do discurso, como, por exemplo, "Ser capaz de falar sobre sua obra e de construir um texto em torno dela".

Consequentemente, a descrição e, mais ainda, a interpretação, são atividades básicas na arte contemporânea. Ao contrário do que afirmam alguns críticos do senso comum sobre a suposta "vacuidade" da arte contemporânea, sentido ou significação de forma alguma estão ausentes: são exigências fundamentais neste mundo. Mas muitas vezes não dizem respeito à obra em si, nem mesmo à arte em geral, mas a toda a sociedade para a qual a arte contemporânea supostamente deve ser um espelho - melhor ainda se for um espelho crítico.

Uma das características específicas da arte contemporânea é a implementação de ideias e sensações ou emoções na mente e no corpo do espectador. Essas sensações, porém, e ao contrário da arte moderna, não são apenas visuais e precisam permitir a possibilidade de uma interpretação. Na arte contemporânea, a "arte visual" tem se tornado mais hermenêutica do que visual. E mesmo quando tende a se tornar cada vez mais "sensacional", como nas tendências mais recentes e populares, as obras não são introduzidas no mundo da arte contemporânea sem um discurso que as acompanhe - algo como um passaporte que permita à obra ultrapassar a fronteira entre o mundo ordinário e o mundo especial da arte contemporânea.

\section{A IMPORTÂNCIA DE MEDIAÇõES}

Ultrapassar as fronteiras da arte em sua acepção tradicional significa também que uma relação direta entre espectadores ordinários e a obra se torna cada vez mais difícil, pois, além do discurso, é necessário um número de mediações para permitir que a obra se estabeleça no mundo da arte (Hennion, 1993; Heinich, 2009c).

Essas mediações pertencem a várias categorias. Pode tratar-se de profissionais, como curadores, críticos de arte, donos de galerias, peritos, historiadores da arte e também moldureiros, transportadores, corretores de seguro, restauradores, gráficos, elétricos, arquitetos de exposições, assis- 
tentes, palestrantes e, eventualmente, fotógrafos... Mediações podem ser instituições, como galerias, museus, centros de arte... Mediações podem ser objetos, como molduras, iluminação, luvas, termômetros, hidrômetros, etiquetas, revistas de arte, livros, fotografias, catálogos, arquivos, contratos e - para não esquecer o mais importante - as paredes de galerias e museus... Mediações podem ser palavras, como a assinatura do artista em cada obra, o nome de um grupo novo, o nome de um gênero novo, nomes de galerias e museus, panfletos, artigos, livros, teses, contratos jurídicos entre uma galeria e o artista, entre o museu e um colecionador particular que possui uma obra... Mediações podem ser imagens e suas reproduções. E podem ser números, a exemplo das datas das obras e seus preços.

Uma última categoria de mediações precisa ser acrescentada à lista: as representações mentais específicas às várias categorias de atores. Mas ao contrário de pessoas, instituições, objetos, palavras, imagens e números, essas representações não podem ser observadas diretamente: podem ser percebidas apenas por meio dos comentários sobre as obras (Heinich, 1998b) ou, às vezes, até por meio de gestos, como no caso do vandalismo (Gamboni, 1997). Esses frames cognitivos ou limites mentais - ou "limites simbólicos" (Lamont, 1992) se manifestam como classificações genéricas (DiMaggio, 1987), critérios axiológicos, modelos biográficos; são mais ou menos incorporados em habilidades visuais ou corporais. Todos eles representam mediações de arte, que determinam a introdução de uma obra em uma categoria e seu posicionamento na escala de valores. Os critérios artísticos implícitos compartilhados por pessoas num contexto determinado são, portanto, mediações fundamentais, apesar de serem quase imperceptíveis - a não ser que sejam especificamente investigados.

Sem essas mediações, nenhuma obra sairia do ateliê do artista e encontraria seu caminho no mundo da arte. E assim que alguns dos critérios necessários para identificar uma obra de arte como tal estiverem ausentes, as mediações necessárias para seu credenciamento artístico se tornam mais ponderáveis e, portanto, mais demoradas. Essas mediações dificilmente existiam na arte clássica, principalmente quando a obra era comissionada; e eram menos necessárias na arte moderna, em que o mercado de arte dominava a maioria das interações de vendedores com compradores. Mas na arte contemporânea as mediações têm se tornado cada vez mais densas em virtude de sua necessidade crescente. Quanto mais uma obra se afasta das expectativas do senso comum, mais necessárias se tornam as mediações entre a obra e o público em geral. Pode-se dizer que as mediações se tornam mais necessárias na medida em que o "campo", para usar um termo de Bourdieu, se torna mais autônomo, mais independente das regras ou expectativas ordinárias. Isso explica a existência atual de numerosos atores dedicados à seleção, circulação e avaliação de obras de arte. 


\section{CíRCULOS DE RECONHECIMENTO}

Esses mediadores ou intermediários de arte não pertencem a uma única categoria, mas a quatro "círculos de reconhecimento", como os chama o historiador de arte britânico Alan Bowness (1989). Ele recorreu à imagem de círculos concêntricos, em cujo centro se encontra a obra. O primeiro círculo representa os colegas, os outros artistas que reconhecem - ou não - o valor de uma nova obra; o segundo círculo, os especialistas em arte, como curadores e críticos de arte; o terceiro círculo, os donos de galerias privadas e colecionadores; o quarto círculo, o público em geral. De círculo em círculo, aumenta o número de seus membros, aumenta também a duração no processo de reconhecimento e diminui o nível de competência. Destarte, esse modelo abarca três dimensões: a proximidade espacial ao artista, a temporalidade do processo de reconhecimento e a relevância desse reconhecimento.

O que está em jogo na arte contemporânea é a inversão do segundo e do terceiro círculo em comparação com a arte moderna. Nesta, os donos de galerias e os colecionadores vinham em primeiro lugar, enquanto os curadores e a maioria dos críticos de arte costumavam descobrir o artista inovador apenas uma geração após suas primeiras exposições; na arte contemporânea, os curadores e críticos de arte seguem imediatamente ao reconhecimento pelos colegas, muitas vezes antes até de sua obra aparecer no mercado privado. Quero citar apenas um exemplo famoso dessa inversão: na virada da década de 1960, Leo Castelli, famoso dono de uma galeria em Nova York, convenceu Alfred Barr, diretor do Museum of Modern Art (MoMA), e Thomas Hess, crítico de arte da revista Art News, que o jovem e totalmente desconhecido Robert Rauschenberg merecia uma exposição no Museu antes mesmo de expor suas obras na galeria de Castelli (Cohen-Solal, 2009). Pela primeira vez, um artista entrou no mundo da arte por meio de uma instituição pública e não de uma galeria. Alguns anos mais tarde, o mesmo artista conquistou o "Leão de Ouro" na Bienal de Veneza - um ponto de virada na transferência de Paris para Nova York como centro de arte internacional (Guilbaut, 1983).

Foi também um ponto de virada na passagem do sistema de arte moderna para a arte contemporânea. Foi, em outras palavras, aquilo que a socióloga da arte francesa, Raymonde Moulin, chamou de mudança de uma arte "orientada pelo mercado" para uma arte "orientada pelo museu" (Moulin, 1992).

\section{ESPACIALIZAÇÃO E INTERNACIONALIZAÇÃO}

O espaço da arte contemporânea também sofreu grandes mudanças. Não se parece mais com o mundo da arte moderna, cuja lenda ainda alimenta nossa imaginação, de uma Paris mítica onde tudo girava em torno de Montmartre e Montparnasse. Hoje, Montmartre e Montparnasse nada mais significam, 
uma vez que as galerias de arte se concentram em Marais, e os artistas franceses preferem viver nos subúrbios para fugir dos altos custos de alojamento no centro de Paris - se não se mudarem para Berlim ou Nova York.

Além disso, esse mundo se especializou muito mais no nível social, focado num público menor e mais elitista do que o público em geral que costumava formar filas em frente aos "Salons de peinture". Ao mesmo tempo, tornou-se muito mais amplo no nível espacial: a arte contemporânea está totalmente internacionalizada. Em seu livro Seven days in the art world (Thornton, 2008), a antropóloga britânica Sarah Thornton fornece algumas informações interessantes sobre essa internacionalização: por exemplo, os passaportes dos dois donos de galerias que ela observou estavam repletos de todos os tipos de vistos; e um artista em ascendência declarou que havia cancelado o contrato de aluguel do seu apartamento porque estava sempre viajando.

$\mathrm{Na}$ arte clássica, a mobilidade estava vinculada à exigência de completar a sua formação como artista num centro artístico como Roma; na arte moderna, mobilidade significava mudar-se para Paris ou passar uma temporada em algum outro lugar (como Picasso costumava fazer); na arte contemporânea, existe toda uma rede de museus, galerias e centros de arte dedicados, especializados e internacionalizados: os artistas simplesmente não conseguem trabalhar se não viajarem, o que vale, sobretudo, para aqueles que praticam performances - onde sua presença é a obra - ou instalações - onde eles mesmos organizam e supervisionam a produção da obra in situ.

Esta é a razão pela qual a arte contemporânea é totalmente cosmopolita. Em um mundo em que o domínio da língua inglesa é um requisito absoluto, ainda mais agora que seu centro se transferiu de Paris para Nova York, como Serge Guilbaut demonstrou em seu livro de 1983, Comment New York vola l'idée d'art moderne (Como Nova York roubou a ideia da arte moderna) - um livro cujo título muito mais adequado seria "Como Nova York roubou a ideia da arte contemporânea".

\section{TEMPORALIDADE: A IDADE DO RECONHECIMENTO}

Devido ao número e à importância de intermediários na arte contemporânea, eles não formam apenas uma parte do "mundo de arte", como diria Becker (1982), mas um "campo", no sentido de Bourdieu: o que significa que são competidores. E devido à prevalência daquilo que chamo de "regime de singularidade" (régime de singularité) na arte moderna e contemporânea, originalidade, inovação e unicidade representam importantes critérios de valor não só na competição entre artistas, mas também entre curadores, críticos e donos de galerias. É por isso que os intermediários competem pela descoberta de artistas que ainda não chamaram a atenção do público, ou que ainda nem entraram no mundo de arte. Consequentemente, tendem a orien- 
tar sua escolha pelos artistas mais jovens com a garantia de serem os primeiros a descobri-los.

Em virtude disto, a temporalidade do reconhecimento sofreu uma aceleração dramática durante as últimas quatro décadas: enquanto um artista moderno, muitas vezes, precisava esperar muito tempo antes de realizar suas primeiras exposições, receber suas primeiras críticas e vender suas primeiras obras, um artista contemporâneo pode experimentar uma ascensão muito rápida na cena artística - como no famoso caso de Jean-Michel Basquiat, que teve um sucesso dramático logo depois de seu $20^{\circ}$ aniversário. Ser jovem tornou-se uma razão para ser bem-sucedido, enquanto uma idade mais avançada já é considerada uma desvantagem.

Este dado sociológico apresenta uma consequência estética importante que concerne à prevalência da arte conceitual sobre outros tipos de tendências artísticas. Em seu livro Old masters and young geniuses, o economista norte-americano David Galenson (2006) demonstrou que a criação artística tende a se dividir em duas tendências principais: os "mestres antigos" (como Cézanne), que demoram muito para alcançar seu alvo por meio de prática empírica e experimentos de longa duração; e os "gênios jovens" (como Picasso), que rapidamente encontram a ideia que pretendem realizar em sua obra. A idade de reconhecimento é, evidentemente, bem diferente nos respectivos casos. Por isto, o privilégio conferido aos artistas jovens, na maioria das vezes em virtude da competição entre os intermediários da arte, tende a criar ou reforçar o privilégio da arte conceitual na arte contemporânea.

\section{NOVAS PRÁTICAS DE COLEÇÃO}

A arte conceitual implica um novo modo de colecionar arte, sendo esta outra característica do novo paradigma. Algumas obras conceituais existem apenas em forma virtual, como um contrato, um certificado, um mapa, um padrão. Mona Thomas, que escreveu um livro sobre colecionadores franceses de arte contemporânea, explica que um dos maiores colecionadores de arte minimalista e conceitual não precisa mostrar as obras que possui quando apresenta suas coleções: ele simplesmente abre um arquivo (Thomas, 1987).

No outro extremo, as pinturas da arte contemporânea quase sempre apresentam dimensões enormes - outra maneira de ignorar a exigência moderna referente à expressão da interioridade do artista, já que suas dimensões significam a mediação de assistentes ou ferramentas especiais. Quando Frank Stella começou a produzir seus quadros enormes, Leo Castelli não sugeriu que os dividisse em duas partes, decidiu tão somente aumentar a porta de entrada da sua galeria (Cohen-Solal, 2009).

Formatos gigantes suscitam este tipo de problemas não só para donos de galerias privadas e, ainda mais, para colecionadores, que já não podem 
mais comprar uma obra para pendurá-la na sala ou no quarto. Esses problemas desafiam também os curadores de museus, que precisam lidar com a questão cada vez mais urgente do armazenamento: quando adquirem algumas pinturas ou instalações enormes, onde podem guardá-las com segurança se seus depósitos tradicionais já estiverem lotados? Isso é um problema constante que os museus de hoje enfrentam.

Instalações representam, ainda, outros problemas quando são comissionadas para serem expostas numa instituição pública. Em virtude dos altos custos de sua construção - que muitas vezes já incluem uma tarifa para o artista -, ela, às vezes, precisa ser financiada parcialmente pela galeria que representa o artista. Mas, neste caso, a quem pertence a obra? À galeria, ao museu, ao artista? E quem terá suas despesas reembolsadas caso a obra seja vendida? As instalações e performances aproximam a economia das artes visuais da economia do teatro, da dança e da música. Assim, a arte contemporânea gera novos problemas jurídicos, para os quais ainda não foram encontradas soluções claras e consensuais.

\section{O PESADELO DO TRANSPORTADOR}

Durante a Bienal de Lyon, uma mandala nepalesa foi criada in situ. Apesar de efêmera, após o espetáculo todos entenderam que ela não poderia ser destruída, já que era considerada uma obra de arte no mesmo nível de obras mais clássicas da arte contemporânea; tampouco poderia permanecer naquele local, pois o espetáculo era um evento temporário. A única solução era transportá-la para o museu que a comissionara. Mas como se transporta algo feito de areia? Os curadores decidiram entrar em contato com a equipe de queimaduras do hospital mais próximo e pedir à equipe responsável pelo transporte de pessoas gravemente feridas que transportasse a mandala.

Essa anedota não é um caso isolado. Uma instalação não pode ser transportada com a mesma facilidade como uma pintura ou escultura, mesmo que sejam grandes. Basta imaginar o que acontece quando o dono de uma galeria precisa enviar a um comprador uma obra de Joseph Beuys feita de cera, aço, feltro, manteiga e uma cadeira: antes de embrulhar os componentes, os transportadores precisam anotar sua posição com o cuidado de um arqueólogo que descreve o conteúdo de uma escavação. E quando a obra consiste de uma geladeira em cima de uma caixa-forte, como a famosa obra de Bertrand Lavier, imagine a dificuldade de convencer os transportadores de que essa geladeira vulgar precisa ser manuseada com o mesmo cuidado dedicado a uma pintura de Rembrandt, já que deveria alcançar seu destino em seu estado perfeito para produzir o efeito desejado pelo artista. A profissão do transportador de arte contemporânea exige habilidades específicas. E poderíamos dizer o mesmo sobre corretores de seguro, mesmo que não tenha tempo para desenvolver esse ponto aqui. 


\section{O PROBLEMA DAS REPRODUÇÕES}

A última categoria de problemas é a das reproduções. A princípio, a arte contemporânea não é uma arte que possa ser reproduzida, por causa da primeira característica que mencionei: o fato de ela consistir não só do objeto proposto pelo artista, mas de todo o contexto da proposição. Por isso, uma fotografia fornece apenas uma evocação muito fraca de uma obra de arte contemporânea - muito mais fraca do que uma fotografia de uma obra clássica ou moderna. Uma descrição verbal - ou até mesmo uma narrativa, uma vez que o tempo muitas vezes exerce um papel importante na relação atual com a obra contemporânea - é muito mais eficiente.

Quero ilustrar isto retornando, uma última vez, ao nosso exemplo seminal: a Fonte de Duchamp. Uma fotografia não basta para descrevê-la fielmente; antes, é necessário explicar as regras do Salon des Indépendants onde foi proposta pela primeira vez (pois a regra da ausência de um júri foi violada pela recusa dos organizadores de considerá-la uma obra que merecia ser exposta); precisamos contar a história de Alfred Stieglitz, o amigo de Marcel Duchamp, e de sua revista de arte The Blind Man, que publicou a primeira foto e o primeiro comentário sobre a obra; devemos fornecer uma lista das galerias, dos colecionadores particulares e dos museus que compraram uma réplica do mictório nas décadas de 1950 e 1960; podemos citar também os contratos de seguro e a extensa literatura produzida sobre o tema juntamente com os muitos protestos e até mesmo atos de vandalismo provocados pelas réplicas etc.

O mesmo vale para as antropometrias de Yves Klein, pois a história de sua criação faz parte da obra; o mesmo se aplica às performances de Josef Beuys ou às instalações de Christian Boltanski, cujo efeito sobre o público não pode ser evocado por nenhuma fotografia. Se a arte contemporânea é uma arte que deve ser narrada e não reproduzida, isto se deve não só à literalidade dos objetos, gestos ou palavras propostas pelo artista, mas também ao contexto em que ela se apresenta - incluindo as expectativas comuns associadas à própria noção de qualquer obra de arte.

Por isto, encerro este artigo sobre a arte contemporânea sem mostrar-lhes nenhuma obra de arte. Mas creio que, mesmo assim, tenham entendido o que quis demonstrar: a arte contemporânea representa um sistema específico ou, em outras palavras, um paradigma, que pouco tem em comum com o paradigma da arte moderna que continua a determinar a percepção artís tica de muitas pessoas - e de muitos artistas. Daí a profunda e continuada crise semelhante à crise científica analisada por Thomas Kuhn, à qual finalmente retornarei para explicar melhor o que está em jogo com a emergência de um novo paradigma artístico, ou seja, uma verdadeira revolução na arte. Quero encerrar com algumas palavras sobre esta questão. 


\section{CONCLUSÃO: UM NOVO PARADIGMA}

O próprio termo "paradigma" tornou-se bastante popular hoje em dia. Mesmo assim, possui um sentido útil e preciso na história das ciências. Espero ter conseguido demonstrar que esse sentido se aplica também à história da arte.

Em The structure of scientific revolutions (1962), Thomas Kuhn empregou o termo "paradigma" para designar a organização geral das noções compartilhadas pelos cientistas em determinada época. Esse conceito ilumina os problemas da inovação conceitual quando esta não se encaixa no paradigma dominante, ou na "ciência normal". Ou essa inovação não é aceita e, talvez, nem mesmo contemplada, ou ela vence a batalha das ideias científicas. Neste último caso, provoca uma mudança paradigmática completa - uma revolução científica. Segundo Kuhn, a história das ciências precisa ser reconstruída a partir desse conceito.

Ao comparar arte e ciência, não alego que sejam semelhantes: isto corresponderia a um uso ordinário da comparação, não a um uso científico. A comparação científica consiste em evidenciar não só as semelhanças, mas também as diferenças entre dois itens para assim revelar suas características específicas. Na verdade, existem grandes diferenças entre ciência e arte: a primeira trata daquilo que o filósofo norte-americano John Searle (Searle, 1995) chamou de "fatos ontologicamente objetivos" - a segunda, de "fatos ontologicamente subjetivos"; a primeira visa à verdade - a segunda, à beleza ou ao sentido; o propósito da primeira é solucionar um mistério - o propósito da segunda é criar uma experiência sensorial, emocional ou intelectual; a primeira permite uma assimilação rápida de um paradigma novo, pois se dirige apenas a especialistas, enquanto a segunda requer muito mais tempo, pois diz respeito também ao público em geral.

No entanto, o conceito do paradigma, apesar de ter sido aplicado primeiro à história das ciências, pode ser aplicado também à história da arte. Ele permite compreender o que aconteceu a partir dos meados do século XIX, ou seja, há um século e meio: a sucessão rápida de duas mudanças paradigmáticas, primeiro da arte clássica para a arte moderna, depois da arte moderna para a arte contemporânea - sendo que esta começou a surgir (na década de 1960) quando a primeira mudança ainda não havia sido completamente assimilada pela cultura popular. Daí a intensidade da crise artística com a qual nos deparamos e a dificuldade que temos de não só resolvê-la, mas até de perceber e entendê-la.

Talvez tenham notado que, para descrever o que podemos chamar de verdadeira revolução artística, não precisei recorrer a nenhuma teoria geral, apenas a um modelo: o modelo criado por Thomas Kuhn com seu conceito do "paradigma". Como qualquer modelo, este também nos permite passar de um assunto e objeto para o outro para esclarecer como funciona, para expor suas 
regras fundamentais ou sua gramática. A análise da gramática da arte contemporânea ou de um paradigma científico não depende de nenhum sistema teórico. Teorias são úteis apenas quando forem modelos que podem ser usados para entender melhor o mundo em que vivemos - mas não quando forem sistemas conceituais que usam o mundo real para construir teorias. Por isso, não usei palavras grandes como "globalização", "identidade", "pós-modernismo", "ascensão do individualismo", "arte em geral", "sociedade”, "cultura" etc., que parecem ter sido criadas especificamente para serem usadas em palestras realizadas em congressos sociológicos: dizem muito sobre as tendências e modas acadêmicas atuais, mas muito pouco sobre seus objetos. Espero que não tenham sentido muita falta destas palavras.

Recebido em 19/10/2013 | Aprovado em 19/03/2014

Nathalie Heinich é socióloga, directeur de recherche no Centre National de la Recherche Scientifique (CNRS), membro do Centre de Recherches sur les Arts et le Langage (CRAL/EHESS, Paris) e membro associado do Laboratoire d'Anthropologie et d'Histoire sur l'Institution de la Culture (LAHIC/CNRS, Ministère de la Culture). Especialista em sociologia das profissões artísticas e das práticas culturais, pesquisa temas como identidade do artista, estatuto do autor, público dos museus, arte contemporânea, sociologia da percepção estética e sociologia dos valores. Entre suas publicações recentes estão, entre outros, "Le Bêtisier du sociologue" (2009) e "Faire voir. L'art à l'épreuve de ses médiations" (2009). 


\section{NOTAS}

* Este artigo resulta de palestra feita pela autora na Research Network Sociology of Arts da European Sociological Association, em evento realizado de 5 a 8 de setembro em Viena, 2012 [N.E.]

\section{REFERÊNCIAS BIBLIOGRÁFICAS}

Becker, Howard. (1982). Art worlds. Berkeley: University of California Press.

Bourdieu, Pierre. (1992). Les règles de l'art. Paris: Minuit. Bowness, Alan. (1989). The conditions of success. How the modern artist rises to fame. Londres: Thames and Hudson.

Camfield, William A. (1989). Marcel Duchamp, Fountain. The Menil collection. Houston: Fine Art Press.

Cohen-Solal, Annie. (2009). Leo Castelli et les siens. Paris: Gallimard.

DiMaggio, Paul. (1987). Classification in art. American Sociological Review, 52/4, agosto, p. 440-457.

Galenson, David. (2006). Old masters and young geniuses. The two life cycles of artistic creativity. Princeton: Princeton University Press.

Gamboni, Dario. (1997). The destruction of art. Iconoclasm and vandalism since the French Revolution. Londres: Reaktion Books. Goffman, Erving. (1981). Forms of talk. Filadélfia: University of Pennsylvania Press.

Goffman, Erving. (1974). Frame analysis. An essay on the organization of experience. Londres: Harper and Row.

Guilbaut, Serge. (1983). Comment New York vola l'idée d'art moderne. Paris : Jacqueline Chambon.

Heinich, Nathalie. (2011). La culture de la célébrité en France et dans les pays anglophones: une approche comparative. Revue Française de Sociologie, 52/2, p. 353-372.

Heinich, Nathalie. (2010). What does "sociology of culture" mean? Notes on a few trans-cultural misunderstandings. Cultural Sociology, 4/2, p. 257-265.

Heinich, Nathalie. (2009a). La fabrique du patrimoine. De la cathédrale à la petite cuillère. Paris: Éditions de la Maison des Sciences de l'Homme. 
Heinich, Nathalie. (2009b). The sociology of vocational prizes: Recognition as esteem. Theory, Culture and Society, 26/5, p. 85-107.

Heinich, Nathalie. (2009c). Faire voir. L'art à l'épreuve de ses médiations. Paris: Les Impressions Nouvelles.

Heinich, Nathalie. (1998a). Le triple jeu de l'art contemporain. Sociologie des arts plastiques. Paris: Minuit.

Heinich, Nathalie. (1998b). L'art contemporain exposé aux rejets. Études de cas. Paris: Jacqueline Chambon.

Hennion, Antoine. (1993). La médiation musicale. Paris: Métailié. Kuhn, Thomas. (1962). The structure of scientific revolutions. Chicago: University of Chicago Press.

Lamont, Michèle. (1992). Money, morals and manners. The culture of the French and the American upper middle class. Chicago: University of Chicago Press.

Moulin, Raymonde. (1992). L'artiste, l'institution et le marché. Paris: Flammarion.

Ramirez, Juan. (1995). Les usines à valeurs. Ecosystème des arts et explosion de l'histoire de l'art. Nîmes: Jacqueline Chambon.

Searle, John. (1995). The construction of social reality. Berkeley: University of California Press.

Thomas, Mona. (1987). Un art du secret. Collectionneurs d'art contemporain en France. Nîmes: Jacqueline Chambon.

Thornton, Sarah. (2008). Seven days in the art world. Londres: Norton and Company. 


\section{PRÁTICAS DA ARTE CONTEMPORÂNEA: UMA ABORDAGEM PRAGMÁTICA A UM NOVO PARADIGMA ARTÍSTICO \\ Resumo}

As "artes" em geral representam uma perspectiva ampla demais para uma abordagem sociológica genuína, por isso, o texto focalizará especificamente as artes visuais e mais especificamente ainda as práticas da arte contemporânea. Apoiando-me em diversas pesquisas, tentarei demonstrar a interdependência recíproca entre as práticas artísticas, as ações dos mediadores ou especialistas em arte e as reações às proposições artísticas. Pretendo demonstrar como a "sociologia pragmática" (como a chamamos na França) ajuda a descrever e entender as características específicas de determinadas ações em seu contexto real - seja ele de natureza espacial ou temporal, institucional, cognitivo ou emocional. Essa questão é ainda mais relevante no caso da arte contemporânea.

\section{PRACTICES OF CONTEMPORARY ART: A PRAGMATIC APPROACH TO A NEW ARTISTIC PARADIGM} cy between artists' practices, mediators' or art specialists' actions and viewers' expectancies and reactions to artistic propositions. I intend to demonstrate how "pragmatic sociology", as we now call it in France, helps in describing and understanding the specificity of given actions in their real context - be it spatial and temporal, institutional, cognitive or emotional. Such an issue is all the more relevant in the case of contemporary art.

\section{Palavras-chave}

Arte contemporânea;

"Sociologia pragmática";

Artes visuais;

Práticas artísticas;

Mediadores.
Keywords

Contemporary art;

Pragmatic sociology;

Visuals arts;

Artist practices;

Mediators. 